\title{
VANITAS: UMA ESTRUTURA EMBLEMÁTICA DE FUNDO MORAL ${ }^{*}$
}

\author{
Yacy-Ara Froner**
}

\begin{abstract}
RESUMO: Este trabalho faz parte da dissertação de mestrado Os símbolos da morte e a morte simbólica, defendida em 1994 pelo Departamento de História da FFLCH/USP. Nosso objetivo é o estudo de duas representações pictóricas do período colonial mineiro, as quais apresentam estruturas formais e conceituais semelhantes. Através destas estruturas, tentaremos resgatar os modelos que deram origem a estas representações, levando em consideração o período e o contexto cultural de onde partem.
\end{abstract}

ABSTRACT: This article is part of a Master's Thesis, The symbols of death and the symbolical death, which was presented in 1994 to the History Department, FFLCH/USP. Our purpose is to study two pictorical representations of the colonial period of Minas Gerais that have the same formal and conceptual structures. By means of these structures, we'll try to bring to mind the models, taking into account the age and cultural context of their production, that originated those representations.

PALAVRAS-CHAVE: Minas Gerais, período colonial, vanitas, emblema, pintura colonial.

KEYWORDS: Minas Gerais, colonial period, vanitas, emblem, colonial picture.

Cada potência possui um rei entre seus atos e um outro entre seus objetos; para a mente, reina o conceito, triunfa a agudeza... Entendimento sem agudeza nem conceitos, é sol sem luz, sem raios. [...] O que é para os olhos a beleza e para os ouvidos a consonância, equivale o mesmo para o entendimento, o conceito. (Benedeto Croce)

* Contamos com o financiamento da CAPES. Agradeço à leitura crítica do Prof. Dr. Ronald Polito.

${ }^{* *}$ Doutoranda pelo Depto. de História-FFLCH/ USP
O reconhecimento dos modelos ou padrões utilizados nos processos de construções figurativas deve procurar apoio nas várias formas de expressão cultural do período onde se encontra inserido, a fim de que seja possível identificar as influências e a ideologia dissimulada por trás das imagens e das mensagem produzidas ao redor de um determinado tema.

A arte figurativa emblemática se desenvolveu desde a Idade Média, sob a forma de hieróglifos, símbolos e alegorias, através de iluminuras de ars moriendi, livros de horas e missais variados. No 
século XVI adquiriu corpo conceitual, atingindo seu apogeu nos séculos XVII e XVIII sob o domínio da cultura barroca, a qual intensificou o uso do recurso figurativo como uma composição voltada para a reflexão e a piedade religiosa.

Os emblemas são representações que ilustram um conceito ou uma idéia, adicionadas de epigramas ou epitáfios, construções escritas, que reforçam as estruturas construtivas dos sistemas figurativos. Geralmente reproduzem conceitos de fundo moral, os quais são apresentados através de sistemas alegóricos reconhecidos apenas pelo caráter cognitivo dos símbolos presentes; desta forma a mensagem é apreendida através de um esforço intelectual, indispensável para se atingir sua compreensão.

O discurso alegórico empregado nos emblemas, empresas e epigramas ${ }^{1}$ demonstra a interdependência entre a linguagem (plástica e discursiva) e a função didática (moral, religiosa, política) destas formas de expressão.

Empresa e epigrama representam, pois, dois modos diferentes de conceber a mesma technopaegnion e o ponto de vista representacional implicado pela palavra emblema (em contrapartida ao ponto de vista literário implicado pelo epigrama) foi adotado por Andrea Alciato sob a influência de hieróglifos egípcios (SCHOPENHAUER. Apud in: PRAZ, 1989, p.18).

Normalmente, conceituamos por emblemas, desenhos alegóricos - introduzidos ou não em textos sob forma de gravuras -, acompanhados de um lema explicativo, destinado a ensinar de forma intuitiva uma verdade moral. Assim, estas formas de expressão constituem uma forma de contraposição da alegoria poética: uma vez que para a alegoria poética as coisas geralmente se convertem em conceitos através de metáforas - com o objetivo de se alcançar a

1. Empresa: conjunto de emblemas de um mesmo conteúdo conceitual ou programa moral; compreensão através da imagem -; do mesmo modo, a imagem plástica utiliza palavras para reafirmar o conceito expresso no pictórico, atribuindo à pintura, não apenas um valor estético, mas o caráter de criação poética.

Assim, as formas plásticas se tornam carregadas de preceitos morais e filosóficos, construídos a partir de um método sistemático de construção intelectual, tornando-se mais importantes pelos seus conceitos intrínsecos e significados inerentes do que pela sua condição estética.

Porém, ainda que Schopenhauer destaque a qualidade expressiva e conceitual da imagem alegórica, diminuindo seu valor estético e pictórico (considerandos secundários neste gênero de representação), a arte voltada para a construção emblemática foi capaz de produzir obras de qualidade estética inegável, como a obra "De symbolicarum quoestionum Libri V”, de Aquile Bocchi (Bolonha, 1555), que recebeu ilustrações gravadas por mestres como Giuliu Bonasone e Agostino Carracci.

A origem destas formas de expressão remonta ao período alexandrino (ut pictura poesis), tendo sido divulgada com os primeiros cristãos e mantida viva ao longo da Idade Média na reproduções dos bestiários, lapidários e reflexões sobre a morte.

Além de representar objetos do mundo visível, simbolizam idéias e sistemas de pensamento, os quais encontram-se associados às concepções e atitudes frente ao universo, a sensibilidade e a mentalidade projetada em um determinado tempo/espaço.

No século XV, a edição de "Hieroglypica" de Horapolo $^{2}$, adquirida em 1419 por um abade florentido, despertou um grande interesse por parte de estudiosos italianos, como Ficino e Alberti, os quais, por sua vez, propagaram seus conceitos, delineando as linhas intelectuais de sua época. Rica em

2. Século II ou IV - Autoria e data não comprovadas. 
sistemas figurativos simbólicos provenientes de tradições antigas, esta obra despertou o apetite da inteligência e dos sentidos, abrindo caminho para um processo de erudição associada à sublimação dos recursos pictóricos. Em 1517 é traduzida para o latim, contribuindo sobremaneira para os estudos emblemáticos através de suas construções fantásticas, que encantaram olhos e imaginação.

Assim, o século XVI, sob a influência dessa tipologia de fontes, adquire um gosto especial pela imagem alegórica e emblemática, como fator de doutrinação moral e religiosa. A poética torna-se fascinada pela construção figurativa, encontrando satisfação em explicar a palavra através do acréscimo de uma representação plástica. Por outro lado, a arte, principalmente aquela voltada para a doutrinação religiosa, apoia-se nos epitáfios a fim de orientar os sentidos aguçados pela cor, pelas formas, luz e sombras.

Uma das obras mais significativas do período foi o Emblematum Liber (1531) de Alciato, um dos livros mais importantes da cultura ocidental e realmente fundamental para a compreensão da época humanista e barroca; o êxito do livro, justificado pelo número de edições consecutivas devidamente ilustradas (gravadas), demonstra a penetração desta literatura e sua influência nas composições seguintes.

$\mathrm{O}$ emblema iria comportar-se como um jogo didático calculado para ensinar de forma intuitiva uma verdade moral, unindo os sentidos e o intelecto, através de uma composição entre a linguagem plástica e a linguagem poética. Ainda no XVI, Cesário Ripa afirma, em sua Iconologia (1593), que algumas imagens têm a capacidade de persuadir pelos olhos, outras movem a vontade mediante o uso das palavras...

Forjados no corpo de uma cultura pautada pelos conflitos religiosos, os séculos que produziram os grandes místicos também fizeram os grandes emblemistas. Sob a égide da devotio moderna, am- bos buscaram a pureza dos sentidos em suas formas de expressão.

Os emblemistas, munidos de fontes clássicas e medievais - conteúdos filosóficos, poéticos e pictóricos de tradições antigas - recorreram a toda sorte de material disponível para a elaboração de seus tratados. Estes, impressos por editores especializados, foram divulgados pelo mundo moderno, influenciando outros gêneros de pinturas e ilustrações, colaborando no processo de doutrinação nos quatro cantos da terra, inclusive nos países coloniais.

Além da ampla divulgação, a composição emblemática, organizando formas e palavras no jogo das ilustrações místicas, adquire uma certa abrangência e totalidade no sistema de educação moral e religiosa da Igreja: se por um lado atinge o espírito através da representação plástica, por outro desperta a consciência e aguça o processo de associação cognitiva através da mensagem exposta nas frases demarcadas (epitáfios).

No final do século XVI o jogo intelectual se intensifica, orientando cada vez mais a construção dos emblemas: quanto mais complexa e repleta de significados for sua execução, mais conceituado será o seu construtor. "Emblemas, Hieróglifos, Apólogos e Empresas são como pedras preciosas no ouro de um elegante discurso" (GRACIÁN, 1649. Apud in: PRÁZ, 1989, p.20.) ${ }^{3}$.

No entanto, a complexidade das formas emblemáticas ao invés de contribuir à sua disseminação promoveu, na verdade, o impedimento de sua leitura: somente alguns poucos privilegiados eram capazes de traduzir e decifrar as ilustrações que cada vez mais se tornaram jogos intelectuais.

3. Observar que foi utilizado construtor e não criador, uma vez que a construção alegórica depende dos sistemas simbólicos, existentes no imaginário, reconhecidos coletivamente e mantidos pela tradição. 
Neste sentido, já no século XVII, Plunche (1748) propõe a claridade como perfeição alegórica no discurso emblemático de fundo religioso, pois, apenas sua compreensão poderia justificar sua existência: "Pois uma obra está apenas destinada a me induzir à meditação, é, portanto ridículo que eu me esforce por entendê-la". A procura de uma maior clareza na transmissão das mensagens morais e religiosas viriam de encontro às propostas da Reforma Tridentina, que reforçando o processo de conversão pelos sentidos, incentivou todos os mecanismos que levassem à submissão pela fé (CROCE, 1957, p.438).

Desse modo, a questão doutrinal do XVII determina uma certa mudança no caráter discursivo do jogo emblemático: se num primeiro momento as palavras tinham por objetivo intensificar o enigma proposto na teia das figurações, em um outro momento elas procuraram integrar e afirmar o significado da construção pictórica, a fim de transmitir uma mensagem mais clara, inteligível e acessível aos fiéis. Assim, a construção emblemática também se modificaria para atender às novas exigências da Igreja.

A necessidade de alimentar o olhar tanto quanto os outros sentidos, de comover a imaginação ao nutrir o coração, o intelecto e a fantasia, produziu toda uma classe de espetáculos, sagrados e profanos, tão freqüentes nos países ibéricos. Procissões, catafalcos, iluminações, arcos, estátuas de cartão, montagens efêmeras, empresas e emblemas, todos os recursos eram empregados para expressar a fé.

Um dos primeiros estudos emblemáticos direcionados à aplicação religiosa foi "Emblème au divise chrestiennes" de Georgette de Monterey (Lyon, 1571). Nesta obra, as empresas de pobreza, castidade, obediência e humildade desfilam marcadas pela riqueza e pela exuberância das volutas, guirlandas de flores e frutos que, por contraste, sugerem a opulência da vida. O princípio de contradição utilizado, propõe o reforço da idéia principal, onde anta- gonismo e oposição atuam como espelho da imagem refletida - o inverso da imagem real. Este recurso, amplamente utilizado por Antônio Vieira em seus Sermões ${ }^{4}$, demonstra uma mudança de sensibilidade nas formas de exposição e expressão religiosa, pautada durante o Renascimento pelo uso da metáfora que reforça o conceirto a partir de imagens consoantes à idéia que se pretende expressar e que agora prefere a oposição e o antagonismo.

Neste contexto, o Concílio de Trento ao reafirmar o papel da imagem como instrumento de doutrinação e manifestação de devoção, irá enfatizar as imagens associadas à reflexão da morte: o crânio torna-se figura indispensável nas representações dos santos e nas construções emblemáticas de fundo religioso. A inspiração destas formas pavorosas, distantes do sentimento italiano, parece proveniente de um dos santos promotores do espírito da Reforma Católica: São Inácio de Loyola, autor de uma obra capital sobre a disciplina da piedade - o Exercícios Espirituais -, no qual apresenta de forma seca e esquemática um modo de oração sistemático, com uma parte dedicada à composição de lugar.

Nos exercícios ignacianos de 1687, recomendase que a primeira meditação se faça de olhos fechados diante de uma caveira. Outros textos como o de Frei Luiz de Grabada (1554) e Luiz de la Puente (1624), dedicam capítulos inteiros às meditações sobre a morte.

Com o Discurso de la Verdad, Miguel Mañara inicia uma série de meditações sobre a vaidade (vanidad/vanitas) das coisas terrenas:

Olhe um sepulcro: adentre com a consideração e olhe seus pais ou sua mulher: perceba o silêncio. Não se ouve ruído algum; apenas o roer dos vermes sutilmente se percebe. E o estrondo dos

4. "Para um homem se ver a si mesmo, são necessárias três coisas: olhos, espelho e luz...” 
pajens e lacaios, onde estão? Aqui termina tudo. Chega a um ossário que está repleto de ossos de defuntos, distingue entre eles o rico do pobre, o sábio do imbecil, o pequeno do grande; todos são ossos, todos caveiras; todos guardam igual figura (MAÑARA, 1675. Apud. in: SEBÁSTIAN, 1986, p.94).

Neste terreno, a literatura emblemática - voltada quase que exclusivamente para o jogo intelectual - se encontra com a literatura religiosa - voltada para a doutrinação moral -, fazendo com que os emblemas se utilizem dos conceitos e recursos citados acima para ilustrar um dos maiores sentimentos projetados pela época barroca: o sentido de efemeridade da vida terrena (vanitas).

Amplamente empregados nas ilustrações de relatos e textos referentes às solemnes exéquias de grandes personagens, homens ilustres, nobres e reis, os emblemas viriam confirmar, através de alegorias, as qualidades do protagonista, além de expor a condição fugaz do ser humano, destacando a fragilidade da vida e a força do tempo.

Sob a luz dos modelos acima mencionados é que estudaremos algumas representações coloniais mineiras, as quais denominaremos pinturas emblemáticas desenvolvidas ao redor do tema da vanidade.

\section{Representações emblemáticas em algumas igrejas de Minas Gerais}

Conforme vimos anteriormente, o tema do "Vanitas" ou "desengano", desenvolve-se no XVIII a partir de reflexões de tradições antigas e de pensamentos filosóficos contemporâneos, através da representação emblemática de fundo moral a vida, percebida como algo perecível e ilusório é contemplada através de uma série de símbolos místicos, sinais, mitos, emblemas, alegorias, signos, atributos - onde o triunfo de um pensamento ocorre a partir de seu poder de expressão.

Em contraponto a testemunhos aparentemente massivos, a constatação de uma evolução profunda da sensibilidade da elite, se impõe de maneira incontestável. É o que chamamos, de uma maneira restrita, de passagem da imagem de conversão - agressiva e pavorosa -, à imagem suporte de meditação, onde no processo de conversão individual intimizada, a Vanidade passa a ser a expressão mais típica (VOVELLE, 1986, p.100).

Apesar deste tipo de produção estar destinado a todas as pessoas - pois encontra-se instalado em locais públicos -, o programa de construção deste imaginário é decorrente de uma proposta da elite, cuja sensibilidade se expressa através de uma reflexão elaborada ao redor do "espírito do tempo", pautada principalmente por uma construção intelectual e uma agudeza de espírito, onde a leitura do pensamento acerca da fragilidade do mundo e de sua destruição eminente perpassa por princípios filosóficos discutidos nos meios eruditos e cristalizados através de motivos alegóricos.

No dicionário latino encontramos: "Vanitas" (Vanus) -1. Aparência vã; aparência não real, mentira, falsidade; 2. Futilidade, frivolidade, vaidade 3. Inutilidade; 4. Vazio, oco, fútil, vaidoso. "Vanum" 1. nada.

O Vanitas, um gênero característico de pintura moral, geralmente remete a dois contextos específicos: citações bíblicas, principalmente aquelas retiradas do livro de Eclesiastes; e pinturas ilustrativas, muitas vezes associadas à Natureza Morta.

O tema da morte, que gerou representações específicas na Idade Média - como a Roda da Fortuna; Os três mortos e os três vivos; a Dança Macabra; Ars moriendi -, também triunfou nas obras de Petrarca e Dante, nos mausoléus de Michelangelo Buonarrotti e nos afrescos de Lorenzo Costa, do resnascimento italiano. Contudo, o retrato macabro ou a natureza morta de fundo meditativo reuniu conceitos de tradições variadas, definindo novos significados às alegorias antigas.

$\mathrm{O}$ retrato macabro, comum no final do século $\mathrm{XV}$ e início do XVI, principalmente nas regiões dos 
Países Baixos, se apresenta geralmente sob a forma de díptico: em uma face aparece a ilustração da vida e em outra a representação da morte; remetendo à juventude e à velhice; ao frescor e à podridão. Este tipo de pintura irá influenciar mais à frente a elaboração de naturezas mortas voltadas para a reflexão macabra.

Um dos exemplos mais conhecidos é o duplo retrato do pintor Hans Burgkmair e sua mulher (1529), que anteriormente se pensava ser obra do próprio artista e posteriormente uma limpeza revelou a assinatura de um de seus colegas de Augsburg - Lucas Furtenagel. O velho casal olha-se num espelho redondo e convexo onde aparece, em vez de seus rostos, suas caveiras

A partir destas obras, uma série de retratos macabros se desenvolveram no decorrer do século XVII através de um gênero que se tornou bem popular: a natureza morta macabra ou Vanitas. A vida silenciosa da natureza que se extingue aparece neste tipo de representação através da composição de coisas vivas e inanimadas, dispostas no quadro de maneira aparentemente desconexa e casual, guardando porém significados intrínsecos. Geralmente acrescido de epitáfios, este tipo de representação pode ser classificado como pinturas emblemáticas, sendo que as frases mais comumente empregadas são: Vanitas, vanitatun; Sic transit glorie mundi; Memento Mori.

A divulgação deste tipo de fonte nos países coloniais contribuiu de maneira relevante no processo de transmissão do pensamento de origem européia, influenciando tanto a literatura quanto as artes plásticas. De acordo com Sylvio de Vasconcelos (1983), o próprio Antonio Franscisco Lisboa haveria de ter recebido lições de composição e princípios de heráldica com o mestre gravador e o abridor de cunhos, João Gomes Batista, contratado pela Casa de Fundição de Vila Rica a partir de 1751. Por outro lado:
Além de Hanna Levy (1978), vários especialistas, como Salomão de Vasconcellos $(1938,1940)$ e Luiz Jardim (1939), afirmaram que muitos artistas brasileiros fizeram uso de gravuras européias como modelos figurativos para a composição de suas obras de arte, sendo destacado o pintor mineiro Manuel da Costa Athayde pelo uso relativamente constante das gravuras da edição ilustrada da Bíblia - "Histoire Sacrée de la Providence et de la Conduite De Dieu Sur les Hommes Depuis le Commencement"- e de gravuras de Rubens.

Ademais dessas constatações, Germain Bazin (1983) identificou o emprego de estruturas emblemáticas na construção de um painel de azulejaria no convento de São Francisco na Bahia (1750). O modelo de inspiração desta obra faz parte da empresa Emblemata Horatiana de Vaenius e segundo o autor é de origem holandesa ou portuguesa.

Carlos Ott (1982) afirmou ter encontrado um exemplar de $O$ Theatro moral de la vida humana y de toda la philosophia de los antigos y modernos (1648) na biblioteca do convento franciscano da Bahia. Esta obra, também ilustrada com uma série de emblemas morais, demonstra a evidência deste tipo de fonte no contexto colonial e sua possível influência nas estruturas de construção plástica, uma vez que a maioria das obras de arte produzida no período se desenvolvia dentro dos esquemas e dos limites da Igreja e da religiosidade.

Contudo, ainda que Luiz Jardim (1939) afirme que nesta tradição estivesse perdido o valor de ação social - contra-reformista -, devemos considerar que a arte deste período se reveste de um outro tipo de valor, em função de um outro tipo de contexto específico: o apelo aos sentidos por meio de pompas e ornamentações grandiosas. Este apelo ocorre, principalmente, com o intuito de manter coesas as formas culturais da tradição do colonizador, além de afirmar, tanto nas formas decorativas quanto nos programas conceituais, o poder do Estado português. 
Minas Gerais, marcada pela proibição do estabelecimento de conventos e ordens primeiras, registra com mais intensidade as questões levantadas acima. Enquanto outras localidades coloniais puderam gozar de uma influência direta da arte erudita eclesiástica e do ecumenismos nas pinturas decorativas, as pinturas decorativas nas igrejas mineiras ficaram, muitas vezes, restritas aos programas e às possibilidades de cada uma irmandade.

Assim, de uma maneira ou de outra, as pinturas decorativas das irmandades brancas, representando santos como que reservados à adoração privada e particular, eram melhor elaboradas, devido à condição privilegiada dessas irmandades, que poderiam contratar os melhores artistas, arquitetos, douradores. Por sua vez, as decorações nos edifícios das irmandades de cor faziam-se aos poucos, com provisões escassas para o pagamento dos ajustes, quase sempre paralisados no meio das obras.

O ecletismo presente nas obras dessas irmandades é capaz de reunir motivos variados, como a pintura das paredes laterais na Igreja Matriz de Santa Efigênia, no Alto da Cruz de Ouro Preto, que apresenta cenas cortesãs de nobres brancos caçando, cantando e cortejando, numa total contradição aparente com o espírito místico de uma das irmandades de cor mais fortes de Villa Rica.

Até o estabelecimento do primeiro bispado da Capitania de Minas Gerais em 1758, quando as bibliotecas dos bispos e de alguns padres mais bem qualificados começaram a influenciar os gostos como se pode observar nos esquemas decorativos a partir da segunda metade do século XVIII - poucas igrejas puderam contar com um modelo mais erudito para sua proposta decorativa.

No entanto, algumas igrejas fogem à regra, como no caso da pintura decorativa da Igreja Nossa Senhora da Conceição de Sabará, pautada pelo refinado gosto, tanto formal quanto conceitual, que se encon- tra exposto nas pinturas em chinesices $^{5}$ das portadas, nas decorações das paredes e dos forros, principalmente no que se refere ao nosso objeto de estudo: a capela de meditação lateral.

Composta por uma estrutura de caixotão marcada em seis quadros, o forro apresenta um esquema de pintura emblemática de conteúdo moral desenvolvido ao redor do tema da efemeridade da vida terrena - Vanitas - pouco comum nas pinturas coloniais brasileiras, no entanto de grande projeção na América espanhola.

Apenas recentemente temos conseguido colocar em evidência que a linguagem emblemática, vigente na cultura européia desde o Renascimento, também cruzou o outro lado do Atlântico; temos testemunhos de sua presença na iberoamérica, tanto na área espanhola quanto na portuguesa (SEBÁSTIAN, 1990, p.249).

A obra de Alciato - Emblematum Liber (1531) - foi traduzida em 1549 para o castelhano foi utilizada pelos jesuítas para uso doutrinal em seus colégios. Além deste texto, no campo da retórica, da gramática e da poética, o livro de Cipriano Soárez De arte rhetorica libri tres ex Aristoteles, Cicerone et Quintiliano deprompti (Coimbra, 1561), também presente nas bibliotecas dos jesuítas, permitiu o contato com exercícios de emblemas e empresas dentro dos ensinamentos de retórica. Na obra de Santiago Sebástian, vários exemplos demonstram a aplicação de conceitos de emblemática em modelos decorativos: o programa moral da casa do fundador de Tunja (Colômbia); os programas místicos de Cuzco e Arequipa baseados em Affectos divinos con emblemas sagradas (Valladolid, 1638) e Pia desideria, do jesuíta Hugo Herman.

5. É de se notar a presença de elementos decorativos orientais em uma das portas lateriais da capela mor, decorada com laca vermelha (proveniente de Macau) e ouro. O mesmo padrão se repete na outra porta, contudo de traços mais rudimentares e materiais menos requintados - no lugar da laca foi utilizado vernelho de mercúrio. 
Outros exemplos da construção emblemática voltada para a meditação barroca admitem correspondência com as obras levantadas neste estudo, como no caso do políptico de Tepotzotlán (México, 1775) dedicado pela ocasião da morte de um mecenas (M.A.S. $)^{6}$. Esta obra remete ao Vanitas existente no nártex da Igreja São Francisco de Assis (Ouro Preto, 1766/1811), um dos poucos exemplos da pintura colonial mineira voltada para este tema.

Comparando a pintura da capela de Nossa Senhora da Conceição de Sabará com a pintura do nártex da Igreja São Francisco de Assis de Ouro Preto (quase um século à frente), podemos perceber que ambas comportam um mesmo sistema compositivo - pintura emblemática cuja temática moral é o conceito de vanitas. Porém, apesar do modelo seguido ser o mesmo, a mensagem moral utiliza exemplos figurativos distintos, demonstrando uma sutil mudança de sensibilidade, princípios e valores de uma época para outra.

Os documentos referentes às obras executadas em Sabará foram destruídos em uma alegada queima de arquivos realizada por ocasião da morte do pároco, vítima de lepra (ÁVILA, 1976). Por sua vez, o teto da Igreja São Francisco de Assis de Ouro Preto também não apresenta uma documentação clara, existindo apenas textos publicados nas revistas do Arquivo Público Mineiro. Desse modo, a carência de documentos precisos quanto ao período, enco-

6. "Interessante es otra lámina del políptico que nos muestra una losa sepulcral presidida por la calavera entre dos velas, una ardiendo y otra que acaba apagarse. Abajo hay un esqueleto uacente entre dos emblemas: a la izquierda un ramo de flores con el lema "Unión entre la variedade", mientras que la derecha vemos un corazón que resiste los golpes que ha permanecido incólume, según declara el lema "Ni el golpe ni las iras". Es preciso destacar aquí que esta escena del corazón atribulado tiene su origen en un libro emblemático, la Schola Cordis de Van Haeften.' (SEBÁSTIAN, 1990, p.249). mendante ou autor, ocasionou uma certa dificuldade na pesquisa dessas pinturas, outorgando ao próprio objeto de estudo as informações adquiridas.

O estado de conservação das pinturas decorativas da Igreja de Nossa Senhora da Conceição apresenta-se atualmente extremamente precário, registrando um elevado processo de degradação contínua, com perdas e desprendimentos recentes, além do escurecimento do verniz, o que dificulta a leitura integral da obra.

A Capela de Nossa Senhora da Conceição de Sabará $^{7}$ foi um dos primeiros refúgios espirituais a ser erguido na Capitania de Minas Gerais. Pelo termo de ereção da Villa Real de Nossa Senhora da Conceição de Sabará - Rio das Velhas, podemos perceber que este arraial foi um dos mais antigos, se destacando pela importância de seu povoamento. Entre os quarenta homens que assinaram testemunhando o termo, está presente um certo Frey Quaresma Franco, provavelmente o único religioso regular presente neste arraial, que alguns dias depois, será eleito para participar da Caza da Câmara erguida na nova vila.

Uma vez que sua construção ocorreu antes da consumação das leis que proibiam a entrada de regulares, não é possível saber se o cargo da administração da igreja estaria ocupado por um Padre Comissário ou um irmão de ordem regular ${ }^{8}$. A presença de um irmão franciscano ou jesuíta poderia ex-

7. Bem Tombado: Igreja Nossa Senhora da Conceição; n.67T, Inscrição n.111; Proprietário: Cúria Arquidiocesana de Belo Horizonte (CARRAZZONI, 1980, p.202).

8. As irmandades religiosas mantinham em sua estrutura a contratação de um padre do Clero Secular que recebia o nome de Padre Comissário, pertencia à Mesa Administrativa e era responsável pelos atos religiosos e instrução dos demais irmãos. Poderia servir à outras paróquias, dependendo da escassez ou não de clérigos existentes na região. 
plicar a erudição do programa empregado nos esquemas decorativos dessa igreja.

A Matriz de Nossa Senhora da Conceição, localizada na Rua do Caminho Novo, foi a primeira Paróquia a ser eregida na vila e esta devoção influenciou para a mudança do nome da vila, anteriormente denominada Vila Real. É quase impraticável a reconstituição de sua história. Em 1701, mediante ato do bispo do Rio de Janeiro, foi instituída a Paróquia de Nossa Senhora da Conceição da antiga Vila Real.

Por volta de 1711 foi inaugurada, provavelmente a partir dos recursos solicitados pelo Governador Geral Antônio Albuquerque Coelho de Carvalho. Fundada a Irmandade do Santíssimo Sacramento, ocupando naturalmente o altar-mor, simbolizando a autoridade suprema da corte celeste e o poder supremo da elite branca, surgiram logo depois as irmandades dos negros e pardos, ocupando os altares laterais. Sendo assim, a Irmandade do Amparo pode conviver sob o mesmo teto desta igreja, ao lado da Irmandade do Santíssimo.

Germain Bazin considera que o trabalho de ornamentação e decoração interna desta igreja não tenha se efetivado após sua construção e, de acordo com o costume da época, tenha demandado um esforço contínuo de mão-de-obra por mais de cinqüenta anos. Este fato explicaria a desigualdade nos aspectos formais e conceituais desta igreja, dividida em três naves, oito altares, um coro e demais capelas e sacristias (BAZIN, 1983, p.121).

Apesar disso, o naturalista francês Auguste de Saint-Hilaire ficou impressionado com a qualidade da decoração e em seus relatos afirma que:

A igreja matriz, dedicada a N.S.da Conceição, é, ao que parece, a mais antiga de todas. Acha-se situada na Vila Velha e é um monumento da riqueza dos primeiros habitantes de Sabará. Os dourados foram aí empregados com espantosa profusão; é dotada de naves laterais com capelas, o que até então não vira em nenhuma parte; as arcadas que separam essas naves do corpo central são guarnecidas de esculturas góticas e todas douradas (SAINT-HILÁIRE, p.133).

Simples em sua fachada, esta igreja impressiona pelo padrão decorativo, tanto pela riqueza das formas quanto pela erudição dos conceitos apresentados. A planta, subdividida em seções autônomas, registra um certo isolamento de cada ambiente. $O$ piso da nave central é de campas e o teto artesoado em caixotões pintados e emoldurados com motivos simbólicos (ÁVILA, 1976, p.34). Enquanto o teto da nave central apresenta pinturas mais simples com alegorias relacionadas à ladainha de Nossa Senhora, no teto e paredes da capela-mor é possível observar quinze quadros representando os chamados mistérios do Rosário, uma composição mais elaborada e complexa.

Junto à porta de acesso à capela do Santíssimo estão pintados quadros alusivos ao Juízo Final, Inferno, Purgatório e Paraíso, introduzindo o fiel a um campo destinado à mais profunda meditação da época barroca: a vanidade. Nesta capela lateral, encontramos um dos mais significativos conjunto de motivos emblemáticos, realizado na pintura do forro, de acordo com o tradicional estilo nacional português, contemporâneo ao primeiro período da arte colonial em Minas Gerais.

A sala de pequenas dimensões e estrutura simples, apresenta nas pinturas de forro um conjunto emblemático de conteúdo filosófico e moral profundo, distinto do que normalmente é concebido a respeito da arte portuguesa, conceituada como uma arte voltada para o exterior, o excessivo, sem conteúdo reflexivo.

A pintura de forro, concebida em uma estrutura de pintura em "caixotão"- própria da primeira metade do século XVIII e geralmente classificada como estilo nacional português - divide-se em seis quadros, reunidos em quatro séries:

Sobre o altar, as insígnias de bispo e cardeal, respectivamente com os epitáfios (Foto 1 e 2): 
I."Vt quid diligitis vanitatem (p.Salm) - Como amais a vaidade...

II. "Irritaverunt in vaitatibus suis"(Cap.32) - excitaram-se em suas vaidades...

Na parte central, as coroas do rei e da rainha (Foto 3 e 4):

III." Florens in Palatio meo vidi (Daniel 4.4) Feliz em meu palácio eu tive uma visão...

IV. "Vanitas vanitatum est omnia vanitas" (Eclesiástes 1.1) - Vaidade das vaidades, tudo é vaidade...

Ainda no centro, a tríplice coroa papal em destaque (Foto 5):

$V$. "Inverto oculos meos ne videant vanitatem" (P.Salm 119: 37) - Volto meus olhos para que eles não vejam a vaidade...

No final da capela, invertida em relação às outras imagens e voltada para a porta, a representação das insígnias da nobreza de armas (Foto 6):

VI. "Si ambulavi in vanitatem e festinavit in dolo pes meus" (Jo 31:5) - Se caminhei na vaidade e se meus pés se apressaram para o engano...

As insígnias, chapéus e coroas respectivas de cada poder, sobre os epitáfios em latim, encontramse dispostos no centro da estrutura de caixotão, em um medalhão emoldurado por caveiras, folhas de acanto, rocalhas, volutas, teias de aranha e cortinados com franjas.

Apesar da presença marcante dos símbolos da morte, a moldura divisória da estrutura apresenta pássaros fênix, um símbolo da ressurreição, bicando ramos de flores contrastadamente vivas, remetendo à ressurreição prometida aos homens "justos".

Pelo fato destas pinturas utilizarem insígnias ao invés de alegorias, não seria possível denominá-las de pintura emblemática. Porém, devido à força discursiva dos epitáfios e a extrema aproximação formal com os conjuntos emblemáticos impressos em discursos fúnebres, além do conteúdo moralizante das mensagens expressas, acredita- mos que estas obras poderiam ser enquadradas nessa categoria.

Apenas no quadro da tríplice coroa papal é possível encontrar ao centro, encimando o emolduramento simétrico, a alegoria da fugacidade do tempo apresentada sob as formas de uma caveira alada. Neste quadro encontra-se registrado o Salmo 119 . Excelência da lei divina:

Desvia meus olhos para que não vejam a vaidade, e vivificame no teu caminho. Confirma ao teu servo a tua promessa, feita aos que te temem.(Salmo 119: 37-38)

Este epitáfio, correspondente à tríplice coroa papal, parece ressaltar a excelência da lei divina sobre a lei dos homens, assegurando aos representantes de Deus na terra a confirmação da promessa de justiça divina. Curiosamente neste mesmo salmo encontra-se a frase:

Assentaram-se príncipes e falaram contra mim, mas o teu servo considerou nos teus decretos. Com efeito, os teus testemunhos são o meu prazer, são os meus conselheiros.(Salmo 119: 23-24)

A representação destes poderes, sua colocação estratégica na sala, a presença dos símbolos da vida e da morte, acabam por afirmar a estrutura dominante, onde os estamentos mais elevados têm o privilégio de serem registrados, enquanto o resto da sociedade é simplesmeste desconsiderado.

Apesar deste tipo de produção estar destinado a todas as pessoas, uma vez que encontra-se instalado em local público, o conteúdo expresso neste imaginário é decorrente de uma proposta da elite, cujo programa demonstra uma sensibilidade voltada para a reflexão do espírito do tempo, que encobre uma outra leitura da fragilidade do mundo e de sua destruição eminente.

A questão da decadência do império colonial português e as esperanças da retomada de poder, presentes no mito sebastianista e do quinto império, 
estariam embutidas neste discurso? Por outro lado, o discurso bíblico correspondente às insígnias reais, remete à passagem onde Nabucodonosor é levado a refletir sobre a dimensão de seu poder, com relação ao poder de Deus.

$\mathrm{Eu}$, Nabucodonosor, estava tranquilo em minha casa, e feliz no meu palácio. Tive um sonho, que me espantou; e, quando estava no meu leito, os pensamentos e as visões da minha cabeça me turbaram. Por isso expedi um decreto, pelo qual fossem introduzidos à minha presença, todos os sábios de Babilônia, para que me fizessem saber a interpretação do sonho. (Daniel 4: 4-6)

Um dos sábios a interpretar o sonho de Nabucodonosor é Daniel, que o alerta para a efemeridade do poder terreno e o aconselha a ser menos soberbo diante dos mistérios da fé.

Portanto, ó rei, aceita o meu conselho, e põe termo em teus pecados pela justiça, e às tuas iniqüidades usando de misericórdia para com os pobres; e talvez se prolongue a tua tranqüilidade (Daniel 4:27)

A crítica feita ao rei babilônio, estaria discretamente endereçada ao monarca português, que sobrepôs seu poder às ordens religiosas, proibindo que elas se instalassem nas áreas mineradoras?

Já no epitáfio destinado à nobreza de armas encontramos uma inscrição do Livro de Jó - Jó declara sua integridade (31:1-40).

Se andei em falsidade e se meu pé apressou-se para o engano; Pese-me Deus em balanças fiéis e conhecerá a minha integridade. (Jó 31:5-6)

Neste caso os defensores da lei e da ordem da Capitania de Minas Gerais, a nobreza de armas, parece isenta de críticas. Por confronto e comparação, observou-se que este primeiro conjunto estudado se encontra mais próximo dos modelos italianos e espanhóis, os quais procuram relacionar a iconografia da morte com o pensamento da mortalidade, fazendo ressaltar o caráter do homem como um ser "passageiro e efê- mero". O padrão estilístico lembra estruturas de grotescos italianos, remetendo mais a uma composição heráldica que a uma estrutura emblemática.

Já o modelo utilizado no Vanitas do nártex da Igreja São Francisco de Assis de Ouro Preto aproxima-se mais do modelo holandês, o qual enfatiza o caráter "perecível" da natureza, do mundo e dos homens, representado principalmente pelas coisas em decomposição.

Devemos ressaltar que a Igreja São Francisco de Assis de Ouro Preto foi construída em um contexto completamente distinto da Matriz de Nossa Senhora da Conceição de Sabará. Do padrão arquitetônico à decoração interna; das irmandades provedoras ao contexto histórico e urbano, tudo parece distanciar estas duas igrejas, diversas em suas formas e história.

O ajuste desta obra ocorreu na segunda metade do século XVIII, quando o cenário social e político já parecia mais tranqüilo e o caráter urbano de Villa Rica melhor sedimentado. Este período encontra-se marcado pela febre construtiva; constantes reformas e novas igrejas eram levantadas todo o tempo, seguindo padrões mais amplos e estilos mais complexos.

Em 1766 data o início da construção, contratada pelo construtor português Domingos Moreira de Oliveira, sendo que o autor do risco foi Antonio Francisco Lisboa - existindo no Museu da Inconfidência uma planta comprovando sua autoria. Alguns anos depois, já elevada a parte estrutural, foi benta a capela e nela instalada a imagem de São Francisco de Assis; em 1772 foram feitos o barrete ${ }^{9}$ da capela mor e as torres, constando como arrematantes, Henrique Gomes de Brito e Luíz Pinheiro Lobo.

Além do risco original, o risco da portada, o lavabo da sacristia, o retábulo do altar-mor e as grandes esculturas que adornam o arco da nave central são de autoria de Antonio Francisco Lisboa.

9. Abóbada formada por 4 triângulos curvilínios, cujos vértices se encontram num ponto central. Elemento decorativo e estrutural. 
O padrão circular, quase militar, parece corresponder às aulas de "Fortificações e Arquitetura Militar”, ministradas por Ludivice, em Portugal, no período de construção do gigantesco convento de Mafra, e que acabou repercutindo no Brasil através das aulas de "Fortificação e Artilharia" (Salvador, 1639 e Rio de Janeiro, 1735).

Por outro lado, também se ajusta ao espírito da Ordem Terceira de São Francisco de Assis, composta em sua maioria por homens brancos, cultos e letrados, que parecem ter procurado expor o espírito de fortaleza e de cavaleiro a serviço do Senhor de seu santo votivo.

De acordo com testemunhos a respeito da vida de São Francisco se diz que certa noite, imerso em seus pensamentos, ele sonhou com um palácio carregado de troféus, quando Cristo vestido de general lhe apareceu dizendo: -Estas armas são tuas. Então despertou sem alcançar a compreensão do enigma, porém, teve outro sonho e entendeu que era melhor servir a Deus que a um soberano deste mundo (SEBÁSTIAN, 1990, p. 296).

Os Apócrifos, Leyenda Dorada, Flos Sanctorum, comercializados livremente pelo novo mundo e publicados amplamente pelos editores, levaram as vidas dos homens santos da Igreja católica a toda cristandade ocidental. Influenciadas por estas leituras, muitas irmandades encontraram nesses textos as indicações necessárias para compor os programas a serem expostos em seus templos, buscando na tradição a elaboração das imagens plásticas - pinturas, esculturas, desenho arquitetônico - que viriam seduzir os fiéis.

Em Minas Gerais, as irmandades utilizaram a riqueza de seus templos como forma de expor seu poder. Concorrendo em fausto, riqueza e requinte, as irmandades também disputavam respeito orgulho e privilégios.

A São Francisco de Assis de Ouro Preto parece reafirmar essa conduta: a escolha estratégica do ter- reno, em um dos pontos centrais e relativamente elevados do espaço urbano, reveste o prédio de uma posição de destaque em relação às outras igrejas; encontra-se de frente a um dos principais eixos de circulação, a atual ladeira do Ouvidor; é visível à distância em todo lado Leste; encontra-se próximo ao centro comercial e administrativo de Vila Rica. Todos esses detalhes parecem ter induzido à escolha do terreno.

Se a implantação do prédio já indica um certo privilégio desta irmandade, a composição da planta e a escolha dos motivos decorativos não seriam relegados a segundo plano. ${ }^{10}$

A grande novidade, relativamente ao partido tradicional, se situa na posição das torres.(NICOLAEFF, 1986/9).

Ocupando grande parte do frontispício, encontramos um portada em esculturas e lavores de pedrasabão, apresentando sobre a verga ${ }^{11}$ do pórtico dois querubins, um de cada lado, sobre festões pendentes. Sobre a portada, aparece um medalhão emoldurado por flores, arrematado por dois anjos que seguram os símbolos da Ordem, que apresenta a figura central de Nossa Senhora da Conceição. Sobre esta, uma coroa de rainha encima a decoração.

Acima deste coroamento, de proporções equivalentes, aparece um medalhão circular. Nenhuma outra igreja possui um medalhão no frontispício tão grande e exuberante, tornando impossível olhar a

10. A posição privilegiada desta irmandade torna-se visível quando, por ocasião da demora para obtenção da licença deliberando a construção da Capela da Ordem - a qual passava por todos os trâmites burocráticos do Estado Colonial Português -, a Irmandade, sem fazer caso da burocracia estatal, inicia a construção dessa Matriz antes da licença oficial chegar, contrapondo-se aos tramites legais numa clara demonstração da força de seus membros.

11. Moldura superior da abertura de portas e portadas. 
matriz sem deter os olhos nesta exímia obra de escultura. No alto da fachada, este grande painel circular guarnecido de molduras apresenta São Francisco ajoelhado, recebendo as chagas no Monte Alverne.

Internamente, o padrão decorativo não decai, demonstrando que, ao contrário das demais irmandades, os recursos para a construção da igreja encontravam-se disponíveis. Raras são as igrejas que mantêm o nível ou até mesmo a totalidade da obra, principalmente no caso das irmandades negras que, de oitava em oitava, juntavam seus parcos recursos para ajustar e contratar seus artesãos.

Diversos artistas, em diferentes épocas, pintaram a matriz: João Baptista de Figueiredo; Manuel Pereira de Carvalho e Francisco Xavier Gonçalves, trataram principalmente do douramento e pintura dos retábulos e da decoração e confecção dos quadro da sacristia. Manuel da Costa Athayde exerceu suas atividades, apenas no início do século XIX - provavelmente entre 1801 e 1812, período em que também trabalha na Igreja São Francisco de Assis de Mariana.

A decoração escultórica interna, também a cargo de Antonio Francisco Lisboa, apresenta uma certa coesão temática, onde Nossa Senhora da Conceição, São Francisco de Assis e a Santíssima Trindade recebem espaços centrais de projeção, demonstrando a presença dos dogmas e a força das irmandades brancas.

Estas obras parecem ter influenciado os esquemas decorativos pictóricos de Manuel da Costa Athayde, como podemos verificar no lavabo que se encontra na sacristia (Foto 7): os anjos sob os pés da alegoria da fé, trazendo o silício e o cordão e os anjos encimados na estrutura de coroamento, apresentando a caveira e a ampulheta, parecem se repetir na pintura decorativa do nártex, registrando em forma e conceitos, os mesmos esquemas artísticos propostos nesta escultura.

Localizada no nártex, uma espécie de ante-sala da nave central, esta pintura de forro encontra-se intermediária entre a portada da entrada e a porta de acesso ao interior da igreja. Emoldurada por rocalhas entre anjos, nuvens e flores, encontramos ao centro da pintura a composição de um Vanitas (Foto 8).

$\mathrm{Na}$ parte superior da moldura, semelhante a um caixilho português, encontramos três anjos: o do lado esquerdo olha para baixo e traz em suas mão o silício e o açoite; o da direita, olhando para cima, traz a caveira e o cordão da ordem; ao centro um outro anjo apresenta um tarja com a inscrição "Vanitas vanitatum".

$\mathrm{Na}$ área interna do emolduramento, como se fosse um quadro, um espelho ou uma abertura para um outro lugar, encontramos uma mesa e sobre ela uma caveira coroada por folhas de acanto - folhas tumulares -, como tributo e louros da glória da morte. Encontra-se sobre livros, réguas, uma pluma de escrita e um pano, que decai sobre a mesa, trazendo o epitáfio "Memento Mori".

À esquerda da caveira encontramos um tinteiro, um vaso de flores, uma flauta e um canhão de luz, como se disparasse bolas de fogo para o céu, sendo uma possível alusão às almas. A sua direita, um castiçal e uma vela ainda acesa, uma ampulheta deitada, um alaúde e uma partitura de música, a qual reproduz uma estrutura compositiva real, não sendo apenas notas decorativas soltas ${ }^{12}$, demandando um estudo mais apurado da composição para sua eventual identificação. Ao fundo, há um quadro ou espelho com a imagem de uma árvore desfolhada, com algumas poucas folhas nas extremidades dos ramos.

Flores, livros, instrumentos de desenho, de escrita e musicais, um espelho com a árvore da vida, uma vela acesa - que se consome pouco a pouco - e uma ampulheta deitada. O tempo civil, das artes e dos prazeres comuns das coisas terrenas, é registrado nesta representação, emoldurada por anjos que

12. Jornal da USP. “A música do céu”. 25-31 de outubro de 1993, p.10. 
ostentam os atributos de São Francisco. Este Vanitas, mais próximo do modelo holandês, apresenta uma natureza morta ou uma natureza silenciosa prestes a se decompor. O registro do tempo é limite, uma fração de segundo entre a vida e a morte, uma passagem entre o tempo terreno e o tempo eterno, grãos finos de uma areia que escorre pela ampulheta ou fumaça de uma vela que se consome. Da Holanda, La Vanité se espalhou por outros países da Europa, católicos e não católicos, condensando uma expressão peculiar, intelectualmente marcada pela inquietude religiosa compartilhada por Shakespeare, Pascal ou por Santa Tereza d'Ávila.

Assim, esta segunda composição, mais próxima do modelo holandês, demonstra uma certa mudança com relação à predileção ou eleição das fontes provenientes da matriz intelectual européia. Se em um primeiro momento, o gosto italiano e espanhol encontra-se registrado no apelo drámatico das obras, no início do XIX, modelos mais intelectualizados demonstram a penetração de outras áreas européias.

No texto "Notas sobre a influência da gravura Flamenga na Pintura Colonial do Rio de Janeiro”, Áurea Pereira da Silva (1978) afirma que as relações artísticas entre os antigos Países Baixos meridionais e o Brasil colonial ocorreram devido às próprias ligações que estes países estabeleciam com Portugal. Desenvolvendo atividades comerciais em Bruges e Antuérpia, os navios portugueses ligavam estas regiões à Lisboa e, a partir daí, a todo o império colonial.

Em 1579, a família Schetz, de origem holandesa, importaria da Antuérpia mais de 113 painéis para a decoração do Engenho dos Erasmos e demais igrejas da região de São Vicente. Através desta negociação, o Brasil teria, então, um dos primeiros contatos com a arte dos Países Baixos. Além disso, livros ilustrados provenientes da Tipografia Plantin Moretus também foram importados, principalmen- te no final do XVIII, resultando em novos modelos a serem copiados.

O Vanitas da Igreja São Francisco de Assis, além de registrar uma outra fonte de inspiração, diferente do padrão reproduzido em Nossa Senhora da Conceição de Sabará, também registra novos ideais e novas perspectivas a serem pleiteadas. Não é mais o poder do Estado e da Igreja a ser expresso, mas sim a sociedade civil dos homens ilustrados, apresentados através da arte e da ciência, registrados nos instrumentos de arquitetura, escrita, nas partituras e instrumentos musicais. Um outro contraste há de se notar no processo de cruzamento entre estas fontes plásticas: enquanto o poder do Estado apresenta-se registrado no Vanitas da Igreja Nossa Senhora da Conceição de Sabará, a qual abriga a Irmandade de Nossa Senhora do Amparo de homens pardos; o Vanitas da Igreja São Francisco de Assis, vinculada a uma elite branca, não apresenta nenhuma alusão ao mesmo poder ${ }^{13}$.

Contudo, este é um espaço público, onde intelectuais como Claudio Manuel da Costa e Tomás Antonio Gonzaga circularam ao lado do escravo João de Deus e do mulato Manoel Dias de Oliveira (músico mineiro, 1738 -1824).

As imagens simbólicas devem ser contempladas, saltam aos olhos do espectador e através deles penetram em seu espírito, manifestando sua natureza, antes que se questione sobre elas. Suas máscaras e difarces caem diante do sentimento que expressam.

Negros, brancos, pardos, letrados ou iletrados, todos se detêm diante da beleza das formas destas pinturas de forro; antes que o conceito toque a inteli-

13. Fritz Teixeira Salles (1969) chama a atenção para o predomínio de irmandades de homens de cor em Sabará - 2 negras e 2 pardas para 3 brancas -, sendo que em Ouro Preto a supremacia das irmandades brancas é marcante - 5 negras, 2 pardas e 10 brancas. 
gência, as sensações elevam o espírito. Improvável não reconhecer a mensagem; impossível não vinculála ao livro do Eclesiastes ${ }^{14}$.

O tempo não faz parte do mundo sensível, e deste modo a única maneira de apresentá-lo é através de analogias. A essência do tempo, sensível à intuição, é registrada em cada época, de acordo com seus valores, suas regras e suas formas. Um século separa estes for-

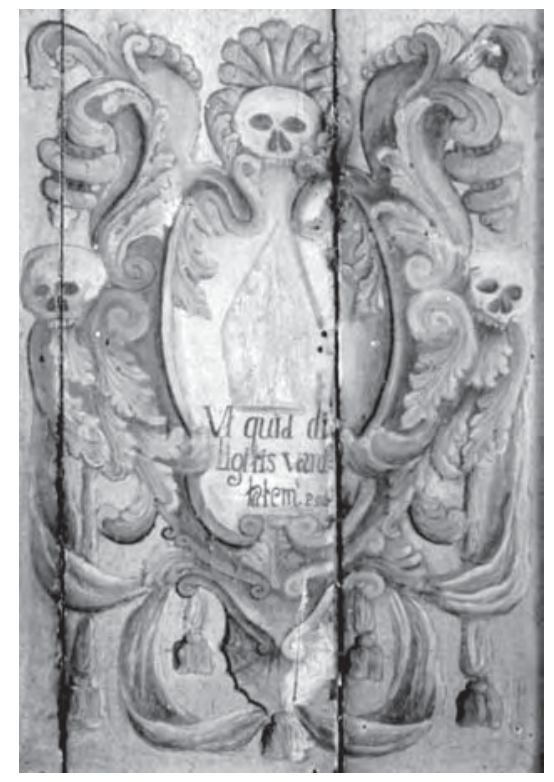

Foto 1

14. "Entre la fé del campesino, que tomaba la animación del ídolo en su sentido realista mas grossero, y la fé del hombre letrado para el que los ceremoniais de culto expresaban meramente una forma simbolica, en alguna parte puede haber un número indefinido de matizes intermedios[...] nos damos cuenta hoy más ros de igreja. No primeiro vemos as marcas rígidas das estruturas dos poderes representados; no segundo as imagens de um novo século demonstram uma nova sensibilidade. No entanto, em ambas pinturas de forro podemos identificar o modelo original, acreditando, assim, ter contribuido para o estudo da arte colonial no Brasil, o qual deve se ater às fontes históricas e não à imaginação sem correspondências paupáveis.

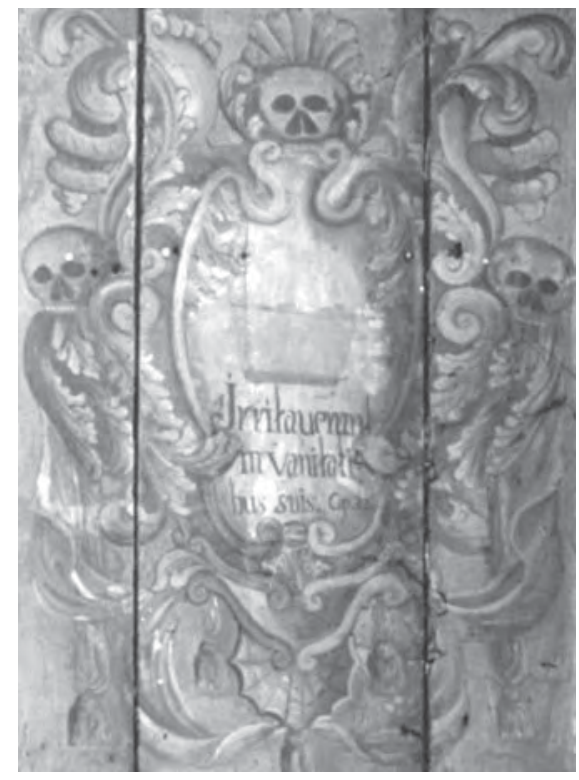

Foto 2

que antes de que en la mente del hombre se dan diversos niveles y de que, por debajo de una teoria intelectual coherente, puede seguir subsistiendo una crencia inconsciente con ella y ligada muy intimamente a sentimentos e deseos inconfesados." (GOMBRICH, 1986, p. 215) 


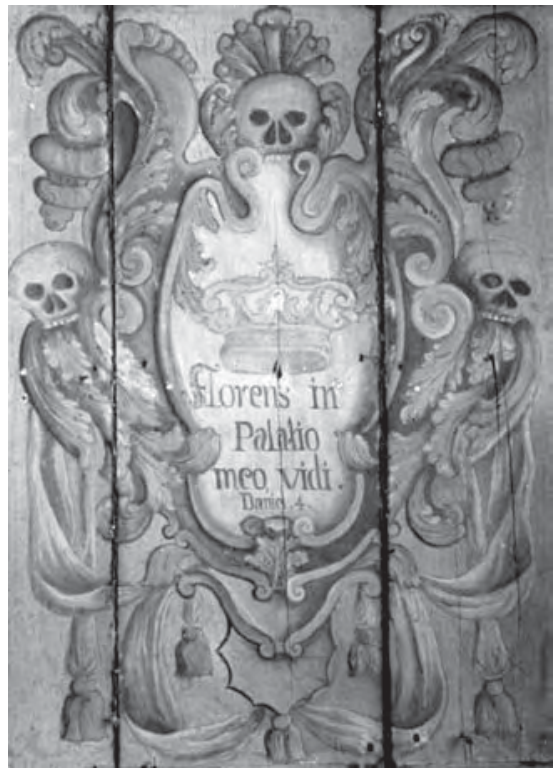

Foto 3

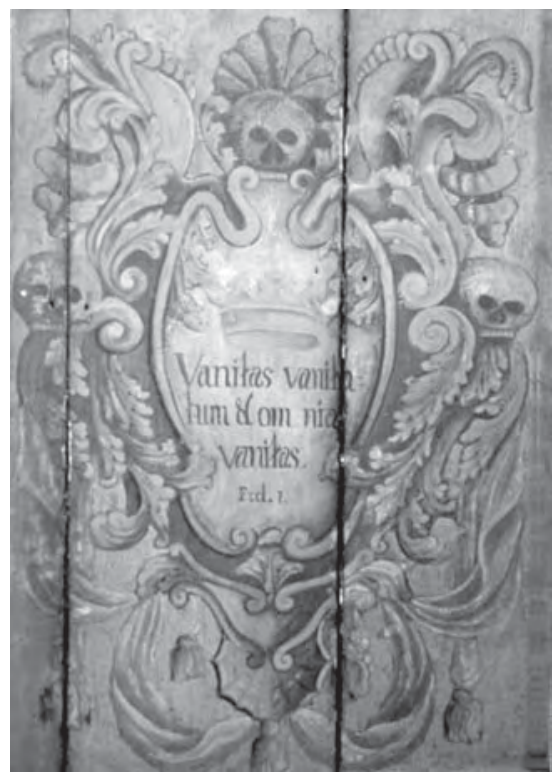

Foto 4

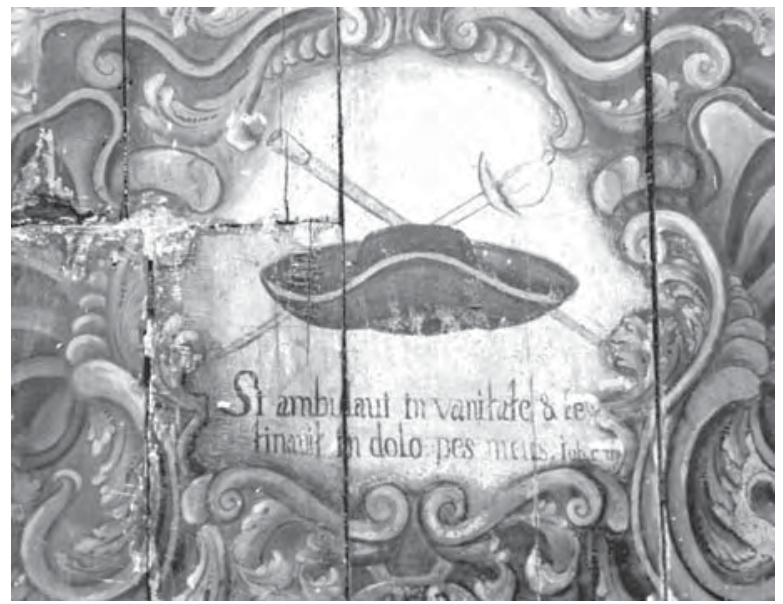

Foto 5 


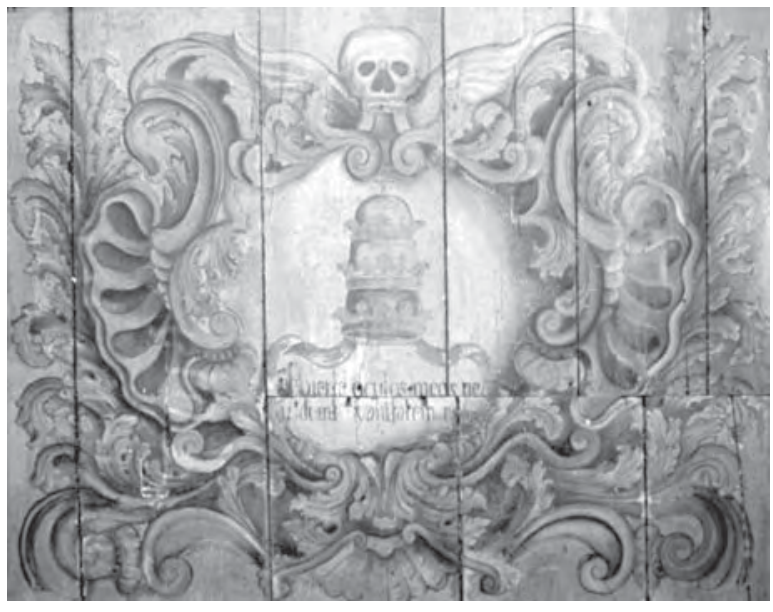

Foto 6

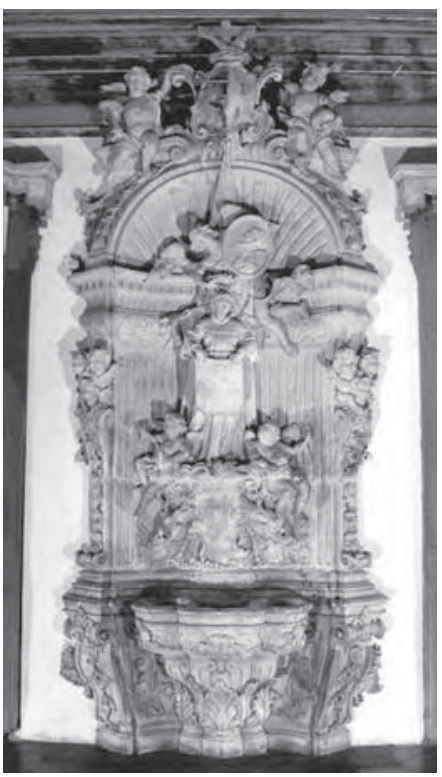

Foto 7

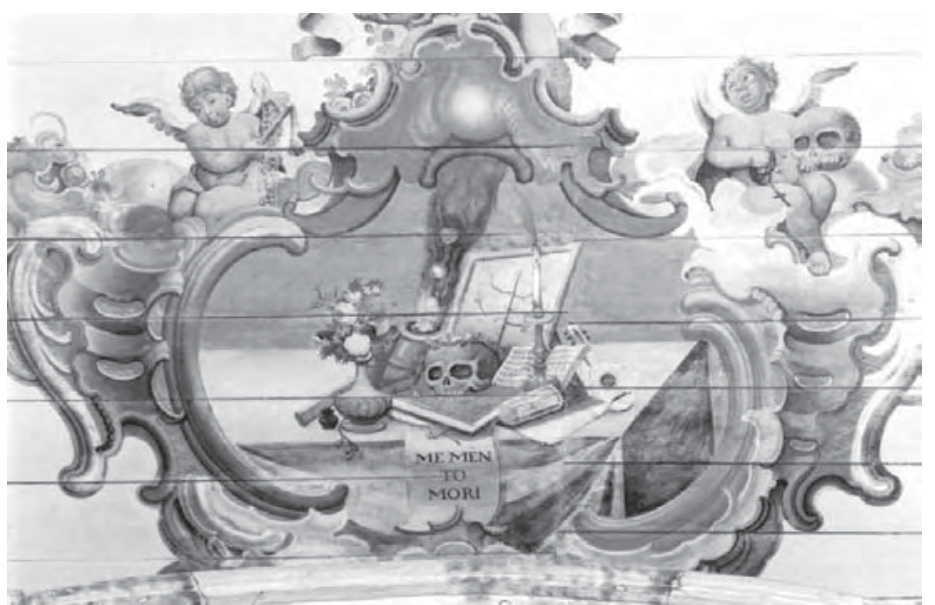

Foto 8 


\section{BIBLIOGRAFIA}

ÁVILA, Affonso. "Igrejas e capelas em Sabará". Barroco, Belo Horizonte, 8: 21-65, 1976.

BAZIN, Germain. Arquitetura Religiosa Barroca no Brasil. Rio de Janeiro, Record, 1983, Tomo I.

CROCE, Benedeto. Storia dell'età barocca. Bari, Giulis Laterza, 1957.

CARRAZZONI, M.E. Guia de bens tombados. Rio de Janeiro, Expressão e Cultura, 1980.

GOMBRICH, E.H. Imagenes simbólicas. Madrid, Alianza, 1986. JARDIM, Luiz. "A pintura decorativa em algumas igrejas antigas de Minas". Revista do SPHAN, Rio de Janeiro, 3: 62$102,1939$.

JORNAL DA USP. "A música do céu". 25-31 de Outubro de 1993.

LEVY, Hannah. "Modelos europeus na pintura colonial". Revista do IPHAN, São Paulo, FAUSP/MEC/IPHAN, n.7, 1978

NICOLAEFF, Alex. "Aspectos da arquitetura da Igreja São Francisco de Assis de Ouro Preto". Barroco. Belo Horizonte, 14: 31-41, 1986/9.

OTT, Carlos. A escola baiana de pintura; 1764-1850. São Paulo, Raízes, 1982.

PRAZ, Mário. Imagenes del barroco: estudios de emblemática. Madrid, Ciruela, 1989.

SAINT-HILÁIRE, A. "Viagens pelo Distrito dos Diamantes e Litoral do Brasil." São Paulo, EDUSP, 1978.

SALLES, Fritz Teixeira de. Associações Religiosas e o Ciclo do Ouro; introdução ao estudo do comportamento social das irmandades de Minas no século XVIII. Belo Horizonte, Centro de estudos mineiros / UFMG, 1963.

SEBÁSTIAN, Santiago. Contrarreforma y barroco. Madrid, Alianza, 1986.

SEBÁSTIAN, Santiago. El Barroco Ibero Americano; mensage iconográfica. Madrid, Encuentro, 1990.

SILVA, Aurea Pereira da. "Notas sobre a influência da Gravura Flamenga na Pintura Colonial do Rio de Janeiro". Barroco, Belo Horizonte, 10: 53-59, 1978-79.

VASCONCELLOS, Diogo de. História antiga das Minas Gerais. Belo Horizonte, Itatiaia, 1974 (2 vol.).

VASCONCELLOS, Salomão de. "Ofícios mecânicos em Vila Rica durante o séc.XVIII". Revista do SPHAN, Rio de Janeiro, MEC, 4: 340-344, 1940.

VASCONCELOS, Salomão de. Mariana e seus templos; era colonial (1703/1797). Belo Horizonte, Gráphica Queiróz Breyner, 1938.

VASCONCELOS, Sylvio de. Mineiridade; ensaio de caracterização. Belo Horizonte, Imprensa Oficial, 1968.

VASCONCELOS, Sylvio de."Antonio Francisco Lisboa e a Nacionalidade", Revista do Conselho Estadual de Cultura de Minas Gerais, Belo Horizonte, 67-71, 1983 (Número Especial).

VIEIRA, Padre Antônio. Sermão da Sexagésima- pregado na capela real no ano de 1655 AEPNSP-OP (FI)

VOVELLE, M. Imagenes Figurales. Paris, Uscher, 1986.

Endereço da Autora: Rua Cardeal Arcoverde, 1663, apto.13 • CEP $05407002 \cdot$ São Paulo $\bullet$ SP • Brasil 